\title{
FASD: Folic acid and Formic Acid - An unholy alliance in the alcohol abusing mother
}

\begin{tabular}{|r|l|}
\hline Journal: & Biochemistry and Cell Biology \\
\hline Manuscript ID & bcb-2017-0079.R1 \\
\hline Manuscript Type: & Mini Review \\
\hline Date Submitted by the Author: & 21 -Jul-2017 \\
\hline $\begin{array}{r}\text { Complete List of Authors: } \\
\text { Is the invited manuscript for } \\
\text { consideration in a Special } \\
\text { Issue? : }\end{array}$ & $\begin{array}{l}\text { Kapur, Bhushan; Sunnybrook Health Science Centre,, Department of } \\
\text { Baber, Marta; University of Toronto, Department of Pharmacology and } \\
\text { Toxicology, Faculty of Medicine }\end{array}$ \\
\hline Keyword: & Formic acid, Folic acid, FASD, methanol, neurotoxicity \\
\hline
\end{tabular}

SCHOLARONE

Manuscripts 
FASD: Folic acid and Formic Acid An unholy alliance in the alcohol abusing mother.

1 FASD: Folic acid and Formic Acid - An unholy alliance in the alcohol abusing mother

Bhushan M. Kapur*1 and Marta Baber ${ }^{2}$

${ }^{1}$ Department of Clinical Pathology, Sunnybrook Health Science Centre, Department of Laboratory Medicine and Pathobiology, Faculty of Medicine, University of Toronto,

${ }^{2}$ Department of Pharmacology and Toxicology, Faculty of Medicine, University of Toronto, Toronto, Ontario, Canada, M5S 1A8

*Address for Correspondence:

Dr. Bhushan M. Kapur

Department of Clinical Pathology

Sunnybrook Health Science Centre

2075 Bayview Ave

Toronto, Ontario

M4N 3M5

Canada

Tele: 9058495507

Fax: 9058494389

email: b.kapur@utoronto.ca 
FASD: Folic acid and Formic Acid An unholy alliance in the alcohol abusing mother.

\section{Abstract Word limit - 200}

Alcohol consumption during pregnancy remains a significant cause of preventable birth defects and developmental disabilities, however, the mechanism of toxicity remains unclear. Methanol is present as a congener in many alcoholic beverages and is formed endogenously. Since ethanol is preferentially metabolized over methanol, it has been found in the sera and CSF of alcoholics. Toxicity resulting from methanol has been attributed to formic acid. Formic acid is present in significantly higher quantities in biofluids of alcoholic patients.

These higher levels can be cytotoxic and cause neuronal cell death. However, the adverse effects can be mitigated by adequate levels of hepatic folic acid, since formic acid elimination depends on folic acid.

During pregnancy, folate concentrations are at least two-fold higher in cord blood then in maternal blood due to increased folate requirements. The reverse has been demonstrated in alcohol abusing pregnancies, suggesting downregulation of folate transporters and low fetal folate levels. Moreover, formic acid can cross the placenta and its adverse effects can be mitigated by folic acid. Thus, the combination of low fetal folate levels and presence of formic acid form a potent cytotoxic combination that may play a significant role in the etiology of fetal alcohol spectrum disorder.

Key words: Formic acid, methanol, folic acid, FASD, neurotoxicity, 
FASD: Folic acid and Formic Acid An unholy alliance in the alcohol abusing mother.

\section{Introduction:}

Fetal alcohol spectrum disorder (FASD) is an umbrella term used to describe a range of

physical, behavioral, and cognitive effects resulting from in-utero exposure to alcohol. The most severe form of FASD is fetal alcohol syndrome (FAS), which is characterized by facial

dysmorphology, growth restriction, and CNS neurodevelopmental abnormalities (Sokol et al.

2003). A wide spectrum of effects has been described, from the milder form known as alcoholrelated neurodevelopmental disorder (ARND), to the extreme manifestation known as FAS. It

has been demonstrated that both the pattern and timing of alcohol consumption play a significant role in the development of FASD. Alcohol is one of the most commonly consumed teratogens worldwide among women of reproductive age(Nevin et al. 2002), and since roughly half of pregnancies are unplanned(Edwards and Werler 2006;Finer and Zolna 2014), alcohol consumption in this cohort poses a significant public health concern. Light-to-moderate drinking in pregnancy is still controversial. Some studies have found that this level of alcohol consumption may lead to adverse neurodevelopmental effects(D'Onofrio et al. 2007; Flak et al. 2014b), while other studies have established no such effects(Falgreen Eriksen et al. 2012;Skogerbo et al. 2012; Underbjerg et al. 2012). Due to the demonstrated potential for harm to the fetus, most health organizations advocate abstinence from alcohol throughout pregnancy (Centers for Disease Control and Prevention 2005;Public Health Agency of Canada 2012). Although the total volume of alcohol intake is an important variable, the number of binge drinking episodes may have a greater effect on the risk for adverse effects (Maier and West 2001). Given that the etiology of FASD is not fully understood and that there is significant 
FASD: Folic acid and Formic Acid An unholy alliance in the alcohol abusing mother.

heterogeneity in terms of fetal effects associated with any amount of alcohol consumption, no "safe" level of alcohol intake during gestation has been established (Centers for Disease Control and Prevention 2005; Charness et al. 2016; Flak et al. 2014a;Sowell et al. 2014)

Axelrod and Daly demonstrated the endogenous formation of methanol (MeOH) from Sadenosylmethionine (SAM) in the pituitary glands of humans and various other mammals(Axelrod and Daly 1965b). In an elegant experiment, Majchrowicz and Mendelson (Majchrowicz and Mendelson 1971a) illustrated the rise in MeOH levels among subjects drinking $\mathrm{MeOH}$-free alcohol, which corroborated the finding by Ericksen and Kulkarni that $\mathrm{MeOH}$ can be produced endogenously(Eriksen and Kulkarni 1963). Most alcoholic beverages also have a small amount of $\mathrm{MeOH}$ as a congener (Roine et al, 1989a ; Sprung et al. 1988a). Both ethanol $(\mathrm{EtOH})$ and $\mathrm{MeOH}$ are metabolized by the same enzymes, alcohol dehydrogenase $(A D H)$, and aldehyde dehydrogenase (ALDH), with the final products being acetic acid and formic acid, respectively. Since $\mathrm{EtOH}$ has a higher affinity for $\mathrm{ADH}$ than $\mathrm{MeOH}$, it is preferentially metabolized (Mani et al. 1970). As a result, $\mathrm{MeOH}$ accumulation from endogenously produced $\mathrm{MeOH}$ and/or $\mathrm{MeOH}$ consumed as part of an alcoholic beverage has been reported in concentrations of up to $2 \mathrm{mmol} / \mathrm{L}$ (Majchrowicz and Mendelson 1971b) and confirmed by others(Iffland and Staak 1990; Jones and Lowinger 1988; Kapur et al. 2007; Roine et al. 1989; Sprung et al. 1988). Altered pharmacokinetic behavior of $\mathrm{MeOH}$ in the presence of EtOH has been demonstrated by various authors(Lesch et al. 1990;Martensson et al. 1988). The presence of MeOH has also been 
FASD: Folic acid and Formic Acid An unholy alliance in the alcohol abusing mother.

suggested as a potential marker for chronic alcohol abuse (Iffland and Staak 1990; Roine et al. 1989)

Neurotoxicity resulting from $\mathrm{MeOH}$ consumption is extensively documented in both humans and animals, and has been attributed to the formation of formic acid from the metabolism of MeOH by ADH and ALDH (Jacobsen and McMartin 1986;Roe 1955;Wood and Buller 1904). Formic acid is eliminated through the one-carbon pathway with folic acid acting as a coenzyme. The rate of formic acid (formate) oxidation and elimination is dependent on adequate levels of hepatic folic acid, particularly hepatic tetrahydrofolate (THF) (Johlin et al. 1987; Tephly 1991). Indeed, to prevent metabolic acidosis in MeOH poisonings, folic acid is currently part of standard of care to drive formic acid oxidation into carbon dioxide and water. It has been demonstrated that significantly higher formate levels are produced when folatedeficient animals are exposed to $\mathrm{MeOH}$, as compared to folate-sufficient animals (Lee et al. 1994;McMartin et al. 1975;Noker et al. 1980). Sokoro and colleagues determined that the halflife of formic acid was 40 minutes in folate-sufficient minipigs compared to 120 minutes in folate-deficient minipigs(Sokoro et al. 2008).

Our group demonstrated the presence of formic acid in the sera of alcoholic patients (Kapur et al. 2007), which was significantly higher ( $p<0.001)$ compared to non-alcohol controls. In an experiment using rat brain slice cultures, we further showed that formic acid concentrations achieved in alcoholic patients' sera can be cytotoxic and can cause neuronal cell death. Formic acid cytotoxicity was shown to be both time- and dose- dependent and it was 
FASD: Folic acid and Formic Acid An unholy alliance in the alcohol abusing mother.

117 found that neuronal cell death could be mitigated by folic acid.

118

There is an abundance of literature implicating acetaldehyde in the pathogenesis of alcohol-related disorders, but to our knowledge there is no literature that has questioned the role of formic acid in chronically alcohol abusing individuals. To better understand the relationship between EtOH toxicity and FASD, it is imperative to consider $\mathrm{MeOH}$ and its metabolite, formic acid, as potential contributors to the teratogenic effects associated with EtOH. Accumulation of $\mathrm{MeOH}$ suggests higher-than-normal levels of formic acid in alcoholdrinking populations. When folate levels are low, elimination of formic acid is slower and its levels are elevated (Sokoro et al. 2008;Noker et al. 1980). Women who are folate-deficient and consume alcohol may have higher levels of formic acid. Since animal studies suggest that formic acid may be toxic to the developing fetus (Brown-Woodman et al. 1995), should these women become pregnant, their fetuses are at greater risk. In this paper, we review the role of formic acid and folic acid in the pathogenesis of FASD.

\section{Formate Metabolism:}

Two non-free radical pathways have been proposed for the conversion of formate to carbon dioxide: oxidation through the catalase-peroxidative system (Chance 1950), and via the one-carbon pool. Formate enters the one-carbon pool by combining with THF to form 10 -formylTHF, a reaction catalyzed by formyl-THF synthetase (Johlin et al. 1987). This is followed by oxidation of 10-formyl-THF to carbon dioxide, mediated by formyl THF dehydrogenase (10- 
FASD: Folic acid and Formic Acid An unholy alliance in the alcohol abusing mother.

139 FTHFDH) (Figure 2).

140
Studies have shown that this is the major route of formate metabolism (Chiao and Stokstad 1977;Johlin et al. 1987;Makar and Tephly 1976;Palese and Tephly 1975) and the predominant one in primates (McMartin et al. 1977). Folic acid plays a major role as a coenzyme in one-carbon metabolism and is a key participant in the biosynthesis of DNA, RNA, and certain amino acids. Formate oxidation to carbon dioxide is dependent upon folic acid in rats, monkeys (McMartin et al. 1977; Noker et al. 1980), and humans (Johlin et al. 1989). Although the liver is the main source for folate, Neymeyer et al. showed the presence of folate and 10-FTHFDH in the retina, optic nerve, and various regions of the rat brain (Neymeyer et al. 1997;Neymeyer and Tephly 1994). In the brain, folate levels were found to be present at concentrations between $3 \%$ and $14 \%$ of those found in the liver. The presence of folate and 10-FTHFDH in the brain suggests that formic acid can be metabolized in this tissue.

Formate can cause oxidative stress by producing free radicals through the Fenton-like reaction (Dikalova et al. 2001; Walling 1975). In this reaction, a hydroxyl radical ('OH) is formed, which in turn oxidizes formate $\left(\mathrm{HCO}_{2}{ }^{\circ}\right)$, forming the carbon dioxide anion radical $\left({ }^{\circ} \mathrm{CO}_{2}\right)$. The ${ }^{\circ} \mathrm{CO}_{2}$ radical then reacts with molecular oxygen, forming carbon dioxide and the cytotoxic reactive oxygen species (ROS) $\cdot \mathrm{O}^{-}$superoxide radical.

$$
\begin{aligned}
& \mathrm{H}_{2} \mathrm{O}_{2}+\mathrm{Fe}^{2+} \rightarrow \cdot \mathrm{OH}+\mathrm{Fe}^{3+}+\mathrm{OH}^{-} \\
& \mathrm{HCO}_{2}^{-}+\cdot \mathrm{OH} \rightarrow \mathrm{CO}_{2}^{-}+\mathrm{H}_{2} \mathrm{O} \ldots \ldots \ldots \\
& \cdot \mathrm{CO}_{2}^{-}+\mathrm{O}_{2} \rightarrow \mathrm{CO}_{2}+. \mathrm{O}^{-} \ldots \ldots \ldots \ldots
\end{aligned}
$$


FASD: Folic acid and Formic Acid An unholy alliance in the alcohol abusing mother. Experiments by Chance have shown that formate can be metabolized by the catalaseperoxidative system (Chance 1950). When anti-oxidants are depleted, increased ROS are formed (Treichel et al. 2004). Formic acid-induced cell damage has been attributed to the generation of the cytotoxic ROS species. Formic acid disrupts mitochondrial electron transport and energy production by inhibiting cytochrome oxidase activity (Nicholls 1975;Nicholls 1976; Sharpe et al. 1982), and causes cell death through the increased production of cytotoxic ROS, secondary to the blockade of the electron transport chain.

The rate of formate oxidation and elimination is dependent on adequate levels of hepatic folic acid, particularly hepatic THF (Johlin et al. 1987;Tephly and McMartin 1974;Tephly 1991). Thus, significantly higher formate levels are achieved when the folate-deficient animals are exposed to MeOH (Dorman et al. 1994; Lee et al. 1994;McMartin et al. 1975;Noker et al. 1980). Tephly has suggested that people with inadequate folate metabolism would be prone to the $\mathrm{MeOH}$ toxicity, since they would have difficulty metabolizing one-carbon units (Tephly 1991). While there is a large body of literature relating maternal folic acid deficiency to fetal neural tube defects and mitochondrial dysfunctions, there are no references relating low dose formic acid to cytotoxicity, and only a few references relating formic acid to mitochondrial inhibition. The latter has been shown in the context of $\mathrm{MeOH}$ intoxication and retinal dysfunctions (Seme et al. 1999;Seme et al. 2001). The toxic effects of formate have also been demonstrated in dissociated primary mouse neural cell cultures (Dorman et al. 1993). The concentration of formate that resulted in 50\% LDH leakage after 8-hour incubation was 
FASD: Folic acid and Formic Acid An unholy alliance in the alcohol abusing mother.

estimated to be $45 \mathrm{mM}$. The total intracellular ATP concentration was significantly reduced

following exposure to either $20 \mathrm{mM}$ or $40 \mathrm{mM}$ of formate for 8 hours, and is consistent with the hypothesis that formate may inhibit mitochondrial function, resulting in decreased intracellular ATP and neurotoxicity.

\section{Folic Acid and Alcohol (EtOH):}

Human beings are fully dependent on dietary sources or supplements for their folate

supply. Folic acid is an essential coenzyme in normal purine, thymidylate, and methionine synthesis, and in many other biochemical reactions involving single-carbon transfers. Chronic alcohol ingestion has been shown to reduce the intestinal absorption of dietary folic acid leading to a decrease in the folate metabolic pool (Halsted et al. 2002b). As a result, folate deficiency is a common finding in chronic alcoholics(Axelrod and Daly 1965a;Eells et al. 2000a; Halsted et al. 2002b;Halsted et al. 2010). This malabsorption has been attributed to the downregulation of folate transporters (Halsted 1980a;Halsted et al. 2002b;Hamid et al. 2007b; Hamid and Kaur 2007a;Thakur and Kaur 2015b). Folate deficiency can lead to a decrease in SAM levels (Miller et al. 1994). The overall status of the one-carbon pathway is also dependent on the levels of methionine and vitamin B6 and B12 (Bailey and Gregory 1999;Barak et al. 1991;Barber et al. 1999; Halsted et al. 2002a;Lucock 2000;McPartlin et al. 1993). A decrease in the folate pool leads to prolonged formate blood levels, since the rate at which formate combines with THF is reduced, which is the first step in its metabolism to carbon dioxide (McMartin et al.1977). This ultimately leads to formate-mediated cytotoxicity. 
FASD: Folic acid and Formic Acid An unholy alliance in the alcohol abusing mother.

During pregnancy, folate requirements increase, as it is needed for DNA synthesis and cell division. Fetal folate levels (cord blood levels) are 2- to 4- fold higher relative to maternal blood levels (Economides et al. 1992;Guerra-Shinohara et al. 2002;Stark et al. 2007). Folate deficiency during pregnancy is associated with abnormalities in the fetus (Greenberg et al. 2011;Safi et al. 2012). The extent to which folic acid is transferred across the placenta and into the fetal circulation is mediated by placental folate transporters folate receptor- $\alpha$ at the microvillous membrane of the syncytiotrophoblast (Bisseling et al. 2004;Solanky et al. 2010), the reduced folate carrier, and the proton-coupled folate transporter (Prasad et al. 1995;Yasuda et al. 2008b;Yasuda et al. 2008a). Hutson and colleagues measured folate in both maternal and umbilical cord blood at the time of delivery in pregnancies with chronic and heavy alcohol exposure and in non-drinking controls. They found that among alcohol-exposed pairs, the fetal to maternal folate ratio was reversed with maternal levels being higher (Hutson et al. 2012). This suggests that chronic and heavy alcohol use in pregnancy impairs folate transport across the placental wall. Folate transporters in the alcohol using/abusing pregnant woman must be downregulated at the placental level. The mechanism is perhaps similar to the downregulation of folate transporters in the context of intestinal absorption of dietary folic acid (Halsted 1980b; Halsted et al. 2002b;Hamid et al. 2007a;Hamid and Kaur 2007b;Thakur and Kaur 2015a). been detected in fetal tissues (Karl et al. 1988). Interestingly, our group found formic acid in the CSF of three of four alcoholic patients, and in all four of the corresponding serum samples 
FASD: Folic acid and Formic Acid An unholy alliance in the alcohol abusing mother.

227 (Kapur et al. 2007). The presence of formic acid in the CSF suggests that either it crossed the

blood-brain barrier or is formed in-situ from the metabolism of water-soluble $\mathrm{MeOH}$ that

crossed the blood-brain barrier. Thus, it is conceivable that formic acid has the physicochemical properties to cross the placental barrier. Using a human placental perfusion model, Hutson and colleagues showed that formic acid does indeed cross the placenta(Hutson et al. 2013) leading to decreased hCG secretion. A decrease in hCG suggests that formic acid may alter steroidogenesis and differentiation of cytotrophoblasts, and has the potential to be toxic to the damage is caused by oxidative stress and mitochondrial dysfunction. developing fetus. The authors also showed that this adverse effect is mitigated by folic acid when it was added to their perfusion model (Hutson et al. 2013). Thus, altered folate concentrations within the placenta and the fetus, combined with increased formic acid, may in part contribute to the deficits observed in FASD. We hypothesize that low folate and high formate contributes to the development of alcohol related brain damage, and that the neuronal

$$
\text { Ethanol and acetaldehyde can be metabolized in the brain, since the activities of }
$$
ethanol-metabolizing enzymes - catalase, CYP2E1, ADH, and ALDH - are shown to be present in this tissue (Brzezinski et al. 1999;Kapoor et al. 2006; Roberto et al. 2006;Sun and Sun 2001;Upadhya et al. 2000; Vasiliou et al. 2006; Yadav et al. 2006;Zimatkin et al. 2006). However, placental CYP2E1 is inducible and its activity has been demonstrated to be variable among heavy drinking women (Rasheed et al. 1997). Using an animal model, Yadav and colleagues showed that CYP2E1 activity is present in different regions of the brain (Yadav et al. 2006).

248 Vasiliou and colleagues suggest in the conclusion of their animal work that "although the 
FASD: Folic acid and Formic Acid An unholy alliance in the alcohol abusing mother.

contribution and CYP2E1 and catalase in ethanol oxidation may be of little significance, these enzymes appear to play a significant role in ethanol metabolism in the brain"(Vasiliou et al.2006). Using brain tissues from human abortuses, Brzezinski and co-workers found CYP2E1 activity in various regions of the developing fetal brain (Brzezinski et al.1999). They stated that "relatively low levels of the P-450 isoform present in conceptal brain may be sufficient to generate reactive intermediates that elicit neuroembryotoxicity following maternal alcohol consumption". Thus, in the context of alcohol consumption in pregnancy, both formic acid and CYP2E1 activity can mediate toxicity in the developing fetus.

In 1985, Stromland followed 30 children of nine mothers who had used alcohol or drugs during pregnancy and found defects of the outer eye region and/or intraocular abnormalities in 90\% of these children (Stromland 1985;Stromland 1987). In a later publication Stromland and Sundelin,(Stromland and Sundelin 1996) described the abnormalities of these same children and found that the children born to mothers who abstained from alcohol during some of their pregnancies were born without birth defects. Anomalies of the outer eye region, like ptosis and strabismus, were frequently found in children with FAS, but were not common in controls. Malformations of the fundus were the most frequently occurring abnormalities in the children with FAS. Forty-eight percent of children showed hypoplasia of the optic nerve head and $49 \%$ had abnormal tortuosity of the retinal arteries.

Visual impairment is one of the most common ophthalmic abnormalities found in children who have been identified as having FAS (Hug et al. 2000;Pinazo-Duran et al. 
FASD: Folic acid and Formic Acid An unholy alliance in the alcohol abusing mother. 1993;Stromland and Pinazo-Duran 2002). The severity of toxic lesions varies among children and can be correlated to the degree of alcohol abuse during pregnancy (Eells et al. 2000b;Pinazo-Duran et al. 1997;Stromland and Pinazo-Duran 1994;Stromland and Sundelin 1996). Formic acid is known to be toxic to the optic nerve. It has been suggested that formate inhibits retinal mitochondrial function and increases oxidative stress (Seme et al. 2001).

Although formic acid and its association with visual impairment has been reported in both animal and human studies, to our knowledge, this association has not been made in children with visual impairment born to mothers who used alcohol during pregnancy.

Brown-Woodman et. al. (Brown-Woodman et al. 1995) assessed the embryonic toxicity of formic acid in an in-vitro explanted rat embryo cultured in rat serum and showed that formic acid can be toxic to the embryo. Eells developed a non-primate (rat) model to study $\mathrm{MeOH}$ induced visual toxicity (Eells 1991). The author stated, "relatively brief exposures to formate appear to produce reversible retinotoxic actions detectable by electroretinography (ERG). Furthermore these ERG alterations occur at formate levels lower than those required to affect flash-evoked cortical potential and lower than those associated with retinal and optic disc edema in humans and monkeys." There are numerous animal studies that report on similar ophthalmologic abnormalities following MeOH administration (Ashwell and Zhang 1994;Eells et al. 1996;Murray et al. 1991;Pinazo-Duran et al. 1993).

Studies on non-rodent Xenopus (frogs) (Yelin et al. 2007) and zebrafish (Marrs et al. 2010) models show that ethanol exposure during early development causes a decrease in the 
FASD: Folic acid and Formic Acid An unholy alliance in the alcohol abusing mother.

expression of eye marker morphogenetic genes Pax6 and $T b \times 3$, which are involved in the formation of the eye(Kozmik 2005; Li et al. 1997). A reduction in the expression of these genes could be the result of overexpression of sonic hedgehog (shh) signaling pathway (Ahlgren et al. 2002;Yelin et al. 2007). To elucidate the mechanism, Kashyap and colleagues (Kashyap et al. 2011) designed a rescue experiment to target both sonic hedgehog (shh) and retinoic acid (RA) signaling pathways that may be affected by ethanol. Ethanol is suggested to act as a competitive inhibitor of the enzyme retinol dehydrogenase, which converts retinol (Vitamin A) to RA, a morphogen for vertebrate limb and nervous system morphogenesis (Duester et al. 1991). Their studies show that ethanol-mediated defects were independent of these pathways suggesting alternate pathways (Ahlgren et al. 2002;Yelin et al. 2007). Perhaps the effects of ethanol on these pathways are both tissue and stage specific (Kiecker 2016). In the zebrafish model, Muralidharan and colleagues (Muralidharan et al. 2015), studied ethanol-mediated retinal tissue defects and folic acid's potential for rescue. They showed that folic acid cosupplementation with ethanol significantly rescued optic nerve and photoreceptor defects.

Human visual functions are also impaired with chronic low-level exposure to $\mathrm{MeOH}$ (Frederick et al. 1984). Toxicity to the visual system produced by either acute, subacute, or chronic $\mathrm{MeOH}$ exposure share a common mechanism, which is most likely mediated by formic acid (Eells et al. 1996;Murray et al. 1991). Formic acid toxicity is likely determined by folic acid and 10-formyltetrahydrofolate dehydrogenase concentrations, which have been shown to be present in both human and rat retinas (Martinasevic et al. 1996). 
FASD: Folic acid and Formic Acid An unholy alliance in the alcohol abusing mother.

The pattern and timing of maternal alcohol consumption play a significant role in the etiology of FASD. Although the total volume of alcohol intake is an important variable, the number of binge drinking episodes, four or more drinks in about two hours for women, may have a greater impact on the risk of adverse effects (Maier and West 2001). Binge drinking leads to high blood EtOH concentration and perhaps even higher levels of formic acid to which the fetus is exposed. Similarly, chronic drinking likely leads to sustained levels of formic acid in the fetus. Since brain development is continuous during the gestational period, chronic or episodic high-level exposure to formic acid may be a significant contributing factor to the development of FASD (Figure 3).

Several studies have shown that there is enzymatic activity in the brain, which can metabolize both EtOH and acetaldehyde (Brzezinski et al. 1999;Kapoor et al. 2006; Roberto et al. 2006;Sun and Sun 2001;Upadhya et al. 2000;Vasiliou et al. 2006; Yadav et al. 2006;Zimatkin et al. 2006). Yadav et al. measured NDMA- $d$ activity in the presence and absence of alcohol (Yadav et al. 2006). They showed a regional difference in CYP2E1-dependent NDMA- $d$ activity that was inducible when there was pre-treatment with EtOH. Significant increase in enzymatic activity was observed in the olfactory lobe, mid brain, hippocampus, hypothalamus, and cerebellum. Bell and co-workers reported a high prevalence of epilepsy and seizure history in children with FASD (Bell et al. 2010a). Impairments, such as cognitive dysfunctions and seizures are associated with the above mentioned regions of the brain(Matthews and Silvers 2004). Thus, it is conceivable that formic acid that crosses the placental barrier and/or is locally produced from $\mathrm{MeOH}$ can significantly impair brain function (Figure 4). 
FASD: Folic acid and Formic Acid An unholy alliance in the alcohol abusing mother.

337

\section{Other Mechanisms of Alcohol Teratogenesis}

A variety of other mechanisms have been proposed to explain the toxic effects of ethanol on the growing fetus. In addition to the link between folate deficiency, oxidative stress, and their respective associations with FASD discussed in this paper, ethanol consumption has also been associated with the augmented production of prostaglandins, which can adversely impact fetal development (Ylikorkala et al. 1988). Interestingly, it has been demonstrated that the administration of a prostaglandin synthesis inhibitor in mice prior to alcohol consumption is associated with a $50 \%$ reduction in malformations relative to mice that receive the inhibitor subsequent to alcohol intake(Randall and Anton 1984).

- plays a minor role in the metabolism of ethanol in the fetus, especially earlier in gestation (McCarver and Hines 2002;Smith et al. 1971). Conversely, the enzymes involved in the nonoxidative metabolism of ethanol are present early in gestation (Bearer et al. 1992;Bearer et al. 1995;Krekels et al. 2012;Stanley et al. 2005). Consequently, the non-oxidative pathways of ethanol metabolism may play a compensatory role in early gestation, in the context of alcohol exposure (Zelner and Koren 2013). Fatty acid ethyl esters (FAEE) are non-oxidative metabolites formed via the breakdown of ethanol. These metabolites have been established as biomarkers of chronic excessive alcohol use in adults (Auwarter et al. 2001;Pragst et al. 2001) and in utero exposure to alcohol (Bearer et al. 1992;Bearer et al. 1999;Caprara et al. 2005; Hungund and 
FASD: Folic acid and Formic Acid An unholy alliance in the alcohol abusing mother.

359 Gokhale 1994;Klein et al. 1999). FAEE have also been established as mediators of toxicity, since

360 they have been demonstrated to reduce cell proliferation, uncouple oxidative phosphorylation,

361 increase the fragility of lysosomes, decrease protein synthesis, increase the formation of lipid

362 droplets, and incorporate into organic bilayers leading to their disordering (Best and Laposata

363 2003;Pragst et al. 2001). FAEE have been shown to accumulate in tissues susceptible to the toxic

364 effects of ethanol, such as the liver, heart, brain, and adipose tissue (Laposata and Lange 1986).

365 The presence of FAEE is associated with liver, pancreatic, myocardial, mitochondrial, and CNS

366 damage (Bora et al. 1996;Gubitosi-Klug and Gross 1996; Haber et al. 1993;Hungund et al.

367 1988;Lange and Sobel 1983;Ponnappa et al. 1994;Szczepiorkowski et al. 1995; Werner et al.

368 1997). Elevated levels of FAEE in the meconium of ethanol-exposed neonates have been linked

369 to deficits in various CNS domains, such as executive functioning and cognition (Min et al.

370 2015;Noland et al. 2003;Peterson et al. 2008).

371
Ethanol has also been associated with the disruption of the endocrine system (Haley et al. 2006), impairment of neurogenesis (Cartwright and Smith 1995; Heaton et al. 2002), a rise in cellular apoptosis (Cartwright and Smith 1995), and alterations in gene expression (Vangipuram et al. 2008). There are a number of risks factors associated with development of FASD, including but not limited to improper nutrition, deficient prenatal care, higher maternal age, paternal drinking, history of substance abuse, having a previous child with FASD, and low education level and socioeconomic status (Esper and Furtado 2014;May and Gossage 2011). Genetic factors may also play a role in the development of FASD (Ramsay 2010). Genetic variants that lead to altered ethanol metabolism can function to modulate the risk of adverse effects (Chernoff 1980). For 
FASD: Folic acid and Formic Acid An unholy alliance in the alcohol abusing mother.

381

instance, variants at the $A D H 1 B\left(A D H 1 B^{*} 2\right.$ and $\left.A D H 1 B^{*} 3\right)$ in the mother or child are associated

with more efficient ethanol metabolism, which in turn has been associated with a mild

protective effect relative to those that do not possess these variants (Arfsten et al.

2004;Jacobson et al. 2006). Ultimately, it is likely that the interplay of various proposed

mechanisms give rise to FASD (Cohen-Kerem and Koren 2003).

\section{Conclusions}

Studies show that methanol and formic acid levels are elevated in human subjects

consuming alcoholic beverages. Alcoholics have low folate levels due to reduced absorption, and

following alcohol consumption, formic acid levels rise and can be neurotoxic. FASD is associated

with significant neurological problems such as behavioural, cognitive and motor impairment

(Chokroborty-Hoque et al. 2014) depression (Pei et al. 2011), and epileptic seizures (Bell et al.

2010b;Nicita et al. 2014). Women who consume alcohol during pregnancy may also have low

folic acid and higher formic acid levels that can be teratogenic to the fetus. (Iffland and Staak

1990;Jones and Lowinger 1988;Kapur et al. 2007; Roine et al. 1989).The role of folate in the

pathogenesis of neural tube defects (Kim 1999) and cardiovascular disease (Stolzenberg-

Solomon et al. 1999) is well established. Moreover, epidemiological studies have shown that

folate supplements can significantly reduce the risk of pancreatic cancer (Fenech 2001) and risk

for cardiovascular diseases (Jiang et al. 2003). Folate requirements increase during gestation and

folate deficiency during pregnancy is associated with abnormalities in the fetus. Alcohol

downregulates folate transport across the placenta resulting in low fetal folate levels. Sustained 
FASD: Folic acid and Formic Acid An unholy alliance in the alcohol abusing mother.

403 levels of formic acid during chronic drinking, and perhaps even higher formate levels during

binge drinking, may explain why binge drinking is particularly harmful to the fetus (Figure 3 ). This

supports our hypothesis that low folic acid and high formic acid levels are a toxic combination in pregnant women who drink.

Pregnant women who consume alcohol and are folate-deficient may accumulate formic acid and produce a high-risk constellation for the fetus. We hypothesize that FASD and associated neuronal damage occurs through formic acid-induced oxidative stress and mitochondrial dysfunction. Folic acid and formic acid play a significant part in the etiology of the very complex syndrome that is FASD.

To our knowledge there is no published literature linking folic acid deficiency and formic acid to FASD, although numerous studies suggest alcohol-mediated oxidative stress as the possible mechanism (Brocardo et al. 2011;Dreosti 1993;Gupta et al. 2016; Muralidharan et al. 2015;Sarmah et al. 2016;Sogut et al. 2017). Thus, treatment using nutrients that have antioxidant properties such as folic acid appear promising.

Our hypothesis raises a number of questions that need to be addressed including: what could be considered clinically relevant concentrations of folic acid and formic acid that cause teratogenicity? What duration of formic acid exposure will result in fetal cytotoxicity? What role might formaldehyde and ethanol-induced folic acid deficiency be on the neurodevelopmental process? Studies in genomic, genetic, and epigenetic mechanism may help in elucidating the 
FASD: Folic acid and Formic Acid An unholy alliance in the alcohol abusing mother.

425 molecular mechanisms of this very complex disorder. It is clear that further research is required

426 to answer these and other questions.

Acknowledgment: Assistance from Dr. Prateek Lala in the creation of the various figures is 431 greatly appreciated.

Financial and competing interest's disclosure: Dr. Baber has been awarded a University of have no role in the design of this study; collection, analysis and interpretation of the data; the writing of this manuscript or the decision to submit this manuscript for publication. The authors have no other relevant affiliations or financial involvement with any organization or entity with a

440 financial interest/conflict in the subject matter. No writing assistance was utilized in the 441 production of this manuscript. 
FASD: Folic acid and Formic Acid An unholy alliance in the alcohol abusing mother.

Reference List

Ahlgren, S.C., Thakur, V., and Bronner-Fraser, M. 2002. Sonic hedgehog rescues cranial neural crest from cell death induced by ethanol exposure. Proceedings of the National Academy of Sciences of the United States of America 99(16): 10476-10481.

Arfsten, D.P., Silbergeld, E.K., and Loffredo, C.A. 2004. Fetal ADH2*3, maternal alcohol consumption, and fetal growth. International Journal of Toxicology 23(1): 47-54.

Ashwell,K.W. and Zhang,L.L, 1994. Optic nerve hypoplasia in an acute exposure model of the fetal alcohol syndrome. Neurotoxicology \& Teratology 16(2): 161-167

Auwarter, V., Sporkert, F., Hartwig, S., Pragst, F., Vater, H., and Diefenbacher, A. 2001. Fatty acid ethyl esters in hair as markers of alcohol consumption. Segmental hair analysis of alcoholics, social drinkers, and teetotalers. Clinical Chemistry 47(12): 2114-2123.

Axelrod, J. and Daly, J. 1965a. Pituitary Gland: Enzymic formation of methanol from 5-adenosylmethionine. Science 150: 892-893.

Axelrod, J. and Daly, J. 1965b. Pituitary Gland: Enzymic formation of methanol from 5-adenosylmethionine. Science 150: 892-893.

Bailey, L.B. and Gregory, J.F.I. 1999. Folate metabolism and requirements. Journal of Nutrition.129(4):779-82.

Barak, A.J., Beckenhauer, H.C., and Tuma, D.J. 1991. Hepatic transmethylation and blood alcohol levels. Alcohol \& Alcoholism.26(2):125-8.

Barber, R.C., Lammer, E.J., Shaw, G.M., Greer, K.A., and Finnell, R.H. 1999. The role of folate transport and metabolism in neural tube defect risk. Molecular Genetics \& Metabolism.66(1):1-9.

Bearer, C.F., Gould, S., Emerson, R., Kinnunen, P., and Cook, C.S. 1992. Fetal alcohol syndrome and fatty acid ethyl esters. Pediatric Research 31(5): 492-495.

Bearer, C.F., Lee, S., Salvator, A.E., Minnes, S., Swick, A., Yamashita, T., and Singer, L.T. 1999. Ethyl linoleate in meconium: a biomarker for prenatal ethanol exposure. Alcoholism: Clinical \& Experimental Research 23(3): 487-493.

Bearer, C.F., Swick, A.R., and Emerson, R.K. 1995. Fetal activity of fatty acid ethyl ester synthases. Res Commun Alcohol Subst Abuse 16(4): 189-194.

Bell, S.H., Stade, B., Reynolds, J.N., Rasmussen, C., Andrew, G., Hwang, P.A., and Carlen, P.L. 2010a. The remarkably high prevalence of epilepsy and seizure history in fetal alcohol spectrum disorders. Alcoholism: Clinical \& Experimental Research 34(6): 1084-1089.

Bell, S.H., Stade, B., Reynolds, J.N., Rasmussen, C., Andrew, G., Hwang, P.A., and Carlen, P.L. 2010b. The remarkably high prevalence of epilepsy and seizure history in fetal alcohol spectrum disorders. Alcoholism: Clinical \& Experimental Research 34(6): 1084-1089. 
FASD: Folic acid and Formic Acid An unholy alliance in the alcohol abusing mother.

Best, C.A. and Laposata, M. 2003. Fatty acid ethyl esters: toxic non-oxidative metabolites of ethanol and markers of ethanol intake. Frontiers in Bioscience 8: e202-e217.

Bisseling, T.M., Steegers, E.A., van den Heuvel, J.J., Siero, H.L., van de Water, F.M., Walker, A.J., SteegersTheunissen, R.P., Smits, P., and Russel, F.G. 2004. Placental folate transport and binding are not impaired in pregnancies complicated by fetal growth restriction. Placenta 25(6): 588-593.

Bora, P.S., Farrar, M.A., Miller, D.D., Chaitman, B.R., and Guruge, B.L. 1996. Myocardial cell damage by fatty acid ethyl esters. Journal of Cardiovascular Pharmacology 27(1): 1-6.

Brocardo, P.S., Gil-Mohapel, J., and Christie, B.R. 2011. The role of oxidative stress in fetal alcohol spectrum disorders. Brain Research Reviews 67(1-2): 209-225.

Brown-Woodman, P.D., Huq, F., Hayes, L., Herlihy, C., Picker, K., and Webster, W.S. 1995. In vitro assessment of the effect of methanol and the metabolite, formic acid, on embryonic development of the rat. Teratology 52(4): 233-243.

Brzezinski, M.R., Boutelet-Bochan, H., Person, R.E., Fantel, A.G., and Juchau, M.R. 1999. Catalytic activity and quantitation of cytochrome P-450 2E1 in prenatal human brain. Journal of Pharmacology \& Experimental Therapeutics.289(3):1648-53.

Caprara, D.L., Brien, J.F., Iqbal, U., Reynolds, J.N., Klein, J., and Koren, G. 2005. A Guinea pig model for the identification of in utero alcohol exposure using fatty acid ethyl esters in neonatal hair. Pediatric Research 58(6): 1158-1163.

Cartwright, M.M. and Smith, S.M. 1995. Increased cell death and reduced neural crest cell numbers in ethanol-exposed embryos: partial basis for the fetal alcohol syndrome phenotype. Alcoholism: Clinical \& Experimental Research 19(2): 378-386.

Centers for Disease Control and Prevention. Alcohol Use in Pregnancy. 2005. 1600 Clifton Road Atlanta, GA 30329-4027 USA, U.S. Department of Health \& Human Services. 14-3-0017.

https://www.cdc.gov/ncbddd/fasd/documents/sg-advisory.pdf Accessed 14 March 2017

Chance, B. 1950. On the Reaction of Catalase Peroxide with Acceptors. Journal of Biological Chemistry 182: $649-658$.

Charness, M.E., Riley, E.P., and Sowell, E.R. 2016. Drinking During Pregnancy and the Developing Brain: Is Any Amount Safe? Trends in Cognitive Sciences 20(2): 80-82.

Chernoff, G.F. 1980. The fetal alcohol syndrome in mice: maternal variables. Teratology 22(1): 71-75.

Chiao, F. and Stokstad, E.L. 1977. Effect of methionine on the metabolism of formate and histidine by rats fed folate/vitamin B-12-methionine-deficient diet. Biochimica et Biophysica Acta.497(1):225-33.

Chokroborty-Hoque, A., Alberry, B., and Singh, S.M. 2014. Exploring the complexity of intellectual disability in fetal alcohol spectrum disorders. . Frontiers in Pediatrics 2: Article 90, 1-9

Cohen-Kerem, R. and Koren, G. 2003. Antioxidants and fetal protection against ethanol teratogenicity. I. Review of the experimental data and implications to humans. Neurotoxicology \& Teratology 25(1): 1-9. 
FASD: Folic acid and Formic Acid An unholy alliance in the alcohol abusing mother.

D'Onofrio, B.M., Van Hulle, C.A., Waldman, I.D., Rodgers, J.L., Rathouz, P.J., and Lahey, B.B. 2007. Causal inferences regarding prenatal alcohol exposure and childhood externalizing problems. Archives of General Psychiatry 64(11): 1296-1304.

Dikalova, A.E., Kadiiska, M.B., and Mason, R.P. 2001. An in vivo ESR spin-trapping study: free radical generation in rats from formate intoxication--role of the Fenton reaction. Proceedings of the National Academy of Sciences of the United States of America.98(24):13549-13553.

Dorman, D.C., Bolon, B., and Morgan, K.T. 1993. The toxic effects of formate in dissociated primary mouse neural cell cultures. Toxicology \& Applied Pharmacology 122(2): 265-272.

Dorman, D.C., Moss, O.R., Farris, G.M., Janszen, D., Bond, J.A., and Medinsky, M.A. 1994.

Pharmacokinetics of inhaled [14C]methanol and methanol-derived [14C]formate in normal and folatedeficient cynomolgus monkeys. Toxicology \& Applied Pharmacology 128(2): 229-238.

Dreosti, I.E. 1993. Nutritional factors underlying the expression of the fetal alcohol syndrome. Annals of the New York Academy of Sciences 678: 193-204.

Duester, G., Shean, M.L., McBride, M.S., and Stewart, M.J. 1991. Retinoic acid response element in the human alcohol dehydrogenase gene $A D H 3$ : implications for regulation of retinoic acid synthesis. Molecular \& Cellular Biology 11(3): 1638-1646.

Economides, D.L., Ferguson, J., Mackenzie, I.Z., Darley, J., Ware, I.I., and Holmes-Siedle, M. 1992. Folate and vitamin B12 concentrations in maternal and fetal blood, and amniotic fluid in second trimester pregnancies complicated by neural tube defects. British Journal of Obstetrics \& Gynaecology 99(1): 2325.

Edwards, E.M. and Werler, M.M. 2006. Alcohol consumption and time to recognition of pregnancy. Maternal \& Child Health Journal 10(6): 467-472.

Eells, J.T. 1991. Methanol-induced visual toxicity in the rat. Journal of Pharmacology \& Experimental Therapeutics 257(1): 56-63.

Eells, J.T., Gonzalez-Quevedo, A., Santiesteban, F.R., McMartin, K.E., and Sadun, A.A. 2000a. Deficiencia de folato y concentraciones elevadas de formato en suero y liquido cefalorraquideo de pacientes con neuropatia optica epidemica [Folic acid deficiency and increased concentrations of formate in serum and cerebrospinal fluid of patients with epidemic optical neuropathy]. [Spanish]. Revista Cubana de Medicina Tropical 52(1): 21-23.

Eells, J.T., Henry, M.M., Lewandowski, M.F., Seme, M.T., and Murray, T.G. 2000b. Development and characterization of a rodent model of methanol-induced retinal and optic nerve toxicity. Neurotoxicology 21(3): 321-330.

Eells, J.T., Salzman, M.M., Lewandowski, M.F., and Murray, T.G. 1996. Formate-induced alterations in retinal function in methanol-intoxicated rats. Toxicology \& Applied Pharmacology 140(1): 58-69.

Eriksen, S.P. and Kulkarni, A.B. 1963. Methanol in normal breath. Science 141: 639-640. 
FASD: Folic acid and Formic Acid An unholy alliance in the alcohol abusing mother.

Esper, L.H. and Furtado, E.F. 2014. Identifying maternal risk factors associated with Fetal Alcohol Spectrum Disorders: a systematic review. European Child \& Adolescent Psychiatry 23(10): 877-889.

Falgreen Eriksen, H.L., Mortensen, E.L., Kilburn, T., Underbjerg, M., Bertrand, J., Stovring, H., Wimberley, T., Grove, J., and Kesmodel, U.S. 2012. The effects of low to moderate prenatal alcohol exposure in early pregnancy on IQ in 5-year-old children. BJOG: An International Journal of Obstetrics \& Gynaecology 119(10): 1191-1200.

Fenech, M. 2001. The role of folic acid and Vitamin B12 in genomic stability of human cells. Mutation Research 475(1-2): 57-67.

Finer, L.B. and Zolna, M.R. 2014. Shifts in intended and unintended pregnancies in the United States, 2001-2008. American Journal of Public Health 104: Suppl-1, S43-S48.

Flak, A.L., Su, S., Bertrand, J., Denny, C.H., Kesmodel, U.S., and Cogswell, M.E. 2014a. The association of mild, moderate, and binge prenatal alcohol exposure and child neuropsychological outcomes: a metaanalysis. Alcoholism: Clinical \& Experimental Research 38(1): 214-226.

Flak, A.L., Su, S., Bertrand, J., Denny, C.H., Kesmodel, U.S., and Cogswell, M.E. 2014b. The association of mild, moderate, and binge prenatal alcohol exposure and child neuropsychological outcomes: a metaanalysis. Alcoholism: Clinical \& Experimental Research 38(1): 214-226.

Frederick, L.J., Schulte, P.A., and Apol, A. 1984. Investigation and control of occupational hazards associated with the use of spirit duplicators. American Industrial Hygiene Association Journal 45(1): 5155.

Greenberg, J.A., Bell, S.J., Guan, Y., and Yu, Y.H. 2011. Folic Acid supplementation and pregnancy: more than just neural tube defect prevention. Revue Obstetricale et Gynecologique 4(2): 52-59.

Gubitosi-Klug, R.A. and Gross, R.W. 1996. Fatty acid ethyl esters, nonoxidative metabolites of ethanol, accelerate the kinetics of activation of the human brain delayed rectifier K+ channel, Kv1.1. Journal of Biological Chemistry 271(51): 32519-32522.

Guerra-Shinohara, E.M., Paiva, A.A., Rondo, P.H., Yamasaki, K., Terzi, C.A., and D'Almeida, V. 2002. Relationship between total homocysteine and folate levels in pregnant women and their newborn babies according to maternal serum levels of vitamin B12. BJOG: An International Journal of Obstetrics \& Gynaecology 109(7): 784-791.

Gupta, K.K., Gupta, V.K., and Shirasaka, T. 2016. An Update on Fetal Alcohol Syndrome-Pathogenesis, Risks, and Treatment. Alcoholism: Clinical \& Experimental Research 40(8): 1594-1602.

Haber, P.S., Wilson, J.S., Apte, M.V., and Pirola, R.C. 1993. Fatty acid ethyl esters increase rat pancreatic lysosomal fragility. Journal of Laboratory \& Clinical Medicine 121(6): 759-764.

Haley, D.W., Handmaker, N.S., and Lowe, J. 2006. Infant stress reactivity and prenatal alcohol exposure. Alcoholism: Clinical \& Experimental Research 30(12): 2055-2064.

Halsted, C.H. 1980a. Folate deficiency in alcoholism.. American Journal of Clinical Nutrition 33(12): 2736- 
FASD: Folic acid and Formic Acid An unholy alliance in the alcohol abusing mother.

2740.

Halsted, C.H. 1980b. Folate deficiency in alcoholism. American Journal of Clinical Nutrition 33(12): $2736-$ 2740 .

Halsted, C.H., Medici, V., and Esfandiari, F. 2010. Influence if Alcohol on Folate Status and Methionine Metabolism in Relation to Alcoholic Liver Disease. In Folate in Health and Disease. Edited by Lynn B.Bailey. Taylor \& Francis Group, CRC Press, Boca Raton pp. 430-448.

Halsted, C.H., Villanueva, J.A., and Devlin, A.M. 2002a. Folate deficiency, methionine metabolism, and alcoholic liver disease. Alcohol.27(3):169-72.

Halsted, C.H., Villanueva, J.A., Devlin, A.M., and Chandler, C.J. 2002b. Metabolic interactions of alcohol and folate. Journal of Nutrition.132(8 Suppl):2367S-2372S.

Hamid, A. and Kaur, J. 2007a. Decreased expression of transporters reduces folate uptake across renal absorptive surfaces in experimental alcoholism. Journal of Membrane Biology 220(1-3): 69-77.

Hamid, A. and Kaur, J. 2007b. Decreased expression of transporters reduces folate uptake across renal absorptive surfaces in experimental alcoholism. Journal of Membrane Biology 220(1-3): 69-77.

Hamid, A., Wani, N.A., Rana, S., Vaiphei, K., Mahmood, A., and Kaur, J. 2007a. Down-regulation of reduced folate carrier may result in folate malabsorption across intestinal brush border membrane during experimental alcoholism. FEBS Journal 274(24): 6317-6328.

Hamid, A., Wani, N.A., Rana, S., Vaiphei, K., Mahmood, A., and Kaur, J. 2007b. Down-regulation of reduced folate carrier may result in folate malabsorption across intestinal brush border membrane during experimental alcoholism. FEBS Journal 274(24): 6317-6328.

Heaton, M.B., Paiva, M., Mayer, J., and Miller, R. 2002. Ethanol-mediated generation of reactive oxygen species in developing rat cerebellum. Neuroscience Letters 334(2): 83-86.

Hug, T.E., Fitzgerald, K.M., and Cibis, G.W. 2000. Clinical and electroretinographic findings in fetal alcohol syndrome. Journal of Aapos: American Association for Pediatric Ophthalmology \& Strabismus 4(4): 200204.

Hungund, B.L. and Gokhale, V.S. 1994. Reduction of fatty acid ethyl ester accumulation by ganglioside GM1 in rat fetus exposed to ethanol. Biochemical Pharmacology 48(11): 2103-2108.

Hungund, B.L., Goldstein, D.B., Villegas, F., and Cooper, T.B. 1988. Formation of fatty acid ethyl esters during chronic ethanol treatment in mice. Biochemical Pharmacology 37(15): 3001-3004.

Hutson, J.R., Lubetsky, A., Eichhorst, J., Hackmon, R., Koren, G., and Kapur, B.M. 2013. Adverse placental effect of formic acid on hCG secretion is mitigated by folic acid. Alcohol \& Alcoholism 48(3): 283-287.

Hutson, J.R., Stade, B., Lehotay, D.C., Collier, C.P., and Kapur, B.M. 2012. Folic acid transport to the human fetus is decreased in pregnancies with chronic alcohol exposure. PLoS ONE [Electronic Resource] 7(5): e38057. 
FASD: Folic acid and Formic Acid An unholy alliance in the alcohol abusing mother.

Iffland, R. and Staak, M. 1990. Methanol und isopropanol als Alkoholismusmarker (Methanol and isopropanol as markers of alcoholism). [German]. Beitrage Zur Gerichtlichen Medizin 48: 173-177.

Jacobsen, D. and McMartin, K.E. 1986. Methanol and ethylene glycol poisonings. Mechanism of toxicity, clinical course, diagnosis and treatment. Medical Toxicology 1(5): 309-334.

Jacobson, S.W., Carr, L.G., Croxford, J., Sokol, R.J., Li, T.K., and Jacobson, J.L. 2006. Protective effects of the alcohol dehydrogenase-ADH1B allele in children exposed to alcohol during pregnancy. Journal of Pediatrics 148(1): 30-37.

Jiang, R., Hu, F.B., Giovannucci, E.L., Rimm, E.B., Stampfer, M.J., Spiegelman, D., Rosner, B.A., and Willett, W.C. 2003. Joint association of alcohol and folate intake with risk of major chronic disease in women. American Journal of Epidemiology 158(8): 760-771.

Johlin, F.C., Fortman, C.S., Nghiem, D.D., and Tephly, T.R. 1987. Studies on the role of folic acid and folate-dependent enzymes in human methanol poisoning. Molecular Pharmacology 31(5): 557-561.

Johlin, F.C., Swain, E., Smith, C., and Tephly, T.R. 1989. Studies on the mechanism of methanol poisoning: purification and comparison of rat and human liver 10-formyltetrahydrofolate dehydrogenase. Molecular Pharmacology 35(6): 745-750.

Jones, A.W. and Lowinger, H. 1988. Relationship between the concentration of ethanol and methanol in blood samples from Swedish drinking drivers. Forensic Science International 37(4): 277-285.

Kapoor, N., Pant, A.B., Dhawan, A., Dwievedi, U.N., Gupta, Y.K., Seth, P.K., and Parmar, D. 2006. Differences in sensitivity of cultured rat brain neuronal and glial cytochrome P450 2E1 to ethanol. Life Sciences. 79(16): 1514-1522.

Kapur, B.M., Vandenbroucke, A.C., Adamchik, Y., Lehotay, D.C., and Carlen, P.L. 2007. Formic acid, a novel metabolite of chronic ethanol abuse, causes neurotoxicity, which is prevented by folic acid. Alcoholism: Clinical \& Experimental Research. 31(12): 2114-2120.

Karl, P.I., Gordon, B.H., Lieber, C.S., and Fisher, S.E. 1988. Acetaldehyde production and transfer by the perfused human placental cotyledon. Science. 242(4876): 273-275.

Kashyap, B., Frey, R.A., and Stenkamp, D.L. 2011. Ethanol-induced microphthalmia is not mediated by changes in retinoic acid or sonic hedgehog signaling during retinal neurogenesis. Alcoholism: Clinical \& Experimental Research 35(9): 1644-1661.

Kiecker, C. 2016. The chick embryo as a model for the effects of prenatal exposure to alcohol on craniofacial development. Developmental Biology 415(2): 314-325.

Kim, Y.I. 1999. Folate and cancer prevention: a new medical application of folate beyond hyperhomocysteinemia and neural tube defects. Nutrition Reviews 57(10): 314-321.

Klein, J., Karaskov, T., and Korent, G. 1999. Fatty acid ethyl esters: a novel biologic marker for heavy in utero ethanol exposure: a case report. Therapeutic Drug Monitoring 21(6): 644-646.

Kozmik, Z. 2005. Pax genes in eye development and evolution. Current Opinion in Genetics \& 
FASD: Folic acid and Formic Acid An unholy alliance in the alcohol abusing mother.

Development 15(4): 430-438.

Krekels, E.H.J., Danhof, M., Tibboel, D., and Knibbe.C.A.J. 2012. Ontogeny of hepatic glucuronidation; methods and results. Current Drub Metabolism 13(6): 728-743.

Lange, L.G. and Sobel, B.E. 1983. Mitochondrial dysfunction induced by fatty acid ethyl esters, myocardial metabolites of ethanol. Journal of Clinical Investigation 72(2): 724-731.

Laposata, E.A. and Lange, L.G. 1986. Presence of nonoxidative ethanol metabolism in human organs commonly damaged by ethanol abuse. Science 231(4737): 497-499.

Lee, E.W., Garner, C.D., and Terzo, T.S. 1994. Animal model for the study of methanol toxicity: comparison of folate-reduced rat responses with published monkey data. Journal of Toxicology \& Environmental Health 41(1): 71-82.

Lesch, O.M., Kefer, J., Lentner, S., Mader, R., Marx, B., Musalek, M., Nimmerrichter, A., Preinsberger, H., Puchinger, H., and Rustembegovic, A. 1990. Diagnosis of chronic alcoholism--classificatory problems. Psychopathology 23(2): 88-96.

Li, H., Tierney, C., Wen, L., Wu, J.Y., and Rao, Y. 1997. A single morphogenetic field gives rise to two retina primordia under the influence of the prechordal plate. Development 124(3): 603-615.

Lucock, M. 2000. Folic acid: nutritional biochemistry, molecular biology, and role in disease processes. Molecular Genetics \& Metabolism., 71(1-2): 121-138.

Maier, S.E. and West, J.R. 2001. Drinking patterns and alcohol-related birth defects. Alcohol Research \& Health: the Journal of the National Institute on Alcohol Abuse \& Alcoholism 25(3): 168-174.

Majchrowicz, E. and Mendelson, J.H. 1971a. Blood methanol concentrations during experimentally induced ethanol intoxication in alcoholics. Journal of Pharmacology \& Experimental Therapeutics 179(2): 293-300.

Majchrowicz, E. and Mendelson, J.H. 1971b. Blood methanol concentrations during experimentally induced ethanol intoxication in alcoholics. Journal of Pharmacology \& Experimental Therapeutics 179(2): 293-300.

Makar, A.B. and Tephly, T.R. 1976. Methanol poisoning in the folate-deficient rat. Nature.261(5562):7156.

Mani, J.C., Pietruszko, R., and Theorell, H. 1970. Methanol activity of alcohol dehydrogenases from human liver, horse liver, and yeast. Archives of Biochemistry \& Biophysics 140(1): 52-59.

Marrs, J.A., Clendenon, S.G., Ratcliffe, D.R., Fielding, S.M., Liu, Q., and Bosron, W.F. 2010. Zebrafish fetal alcohol syndrome model: effects of ethanol are rescued by retinoic acid supplement. Alcohol 44(7-8): 707-715.

Martensson, E., Olofsson, U., and Heath, A. 1988. Clinical and metabolic features of ethanol-methanol poisoning in chronic alcoholics. Lancet 1(8581): 327-328. 
FASD: Folic acid and Formic Acid An unholy alliance in the alcohol abusing mother.

Martinasevic, M.K., Green, M.D., Baron, J., and Tephly, T.R. 1996. Folate and 10-formyltetrahydrofolate dehydrogenase in human and rat retina: relation to methanol toxicity. Toxicology \& Applied Pharmacology 141(2): 373-381.

Matthews, D.B. and Silvers, J.R. 2004. The use of acute ethanol administration as a tool to investigate multiple memory systems. Neurobiology of Learning \& Memory 82(3): 299-308.

May, P.A. and Gossage, J.P. 2011. Maternal risk factors for fetal alcohol spectrum disorders: not as simple as it might seem. Alcohol Health \& Research World 34(1): 15-26.

McCarver, D.G. and Hines, R.N. 2002. The ontogeny of human drug-metabolizing enzymes: phase II conjugation enzymes and regulatory mechanisms. Journal of Pharmacology \& Experimental Therapeutics 300(2): 361-366.

McMartin, K.E., Makar, A.B., Martin, G., Palese, M., and Tephly, T.R. 1975. Methanol poisoning. I. The role of formic acid in the development of metabolic acidosis in the monkey and the reversal by 4methylpyrazole. Biochemical Medicine.13(4):319-33.

McMartin, K.E., Martin-Amat, G., Makar, A.B., and Tephly, T.R. 1977. Methanol poisoning. V. Role of formate metabolism in the monkey. Journal of Pharmacology \& Experimental Therapeutics 201(3): 564572.

McPartlin, J., Halligan, A., Scott, J.M., Darling, M., and Weir, D.G. 1993. Accelerated folate breakdown in pregnancy. Lancet 341(8838): 148-149.

Miller, J.W., Nadeau, M.R., Smith, J., Smith, D., and Selhub, J. 1994. Folate-deficiency-induced homocysteinaemia in rats: disruption of S-adenosylmethionine's co-ordinate regulation of homocysteine metabolism. Biochemical Journal.298 ( Pt 2):415-9.

Min, M.O., Singer, L.T., Minnes, S., Wu, M., and Bearer, C.F. 2015. Association of fatty acid ethyl esters in meconium and cognitive development during childhood and adolescence. Journal of Pediatrics 166(4): 1042-1047.

Muralidharan, P., Sarmah, S., and Marrs, J.A. 2015. Zebrafish retinal defects induced by ethanol exposure are rescued by retinoic acid and folic acid supplement. Alcohol 49(2): 149-163.

Murray, T.G., Burton, T.C., Rajani, C., Lewandowski, M.F., Burke, J.M., and Eells, J.T. 1991. Methanol poisoning. A rodent model with structural and functional evidence for retinal involvement. Archives of Ophthalmology 109(7): 1012-1016.

Nevin, A.C., Parshuram, C., Nulman, I., Koren, G., and Einarson, A. 2002. A survey of physicians knowledge regarding awareness of maternal alcohol use and the diagnosis of FAS. BMC Family Practice 3: 2 .

Neymeyer, V., Tephly, T.R., and Miller, M.W. 1997. Folate and 10-formyltetrahydrofolate dehydrogenase (FDH) expression in the central nervous system of the mature rat. Brain Research.766(1-2):195-204.

Neymeyer, V.R. and Tephly, T.R. 1994. Detection and quantification of 10-formyltetrahydrofolate dehydrogenase (10-FTHFDH) in rat retina, optic nerve, and brain. Life Sciences 54(22): L395-L399. 
FASD: Folic acid and Formic Acid An unholy alliance in the alcohol abusing mother.

Nicholls, P. 1975. Formate as an inhibitor of cytochrome c oxidase. Biochemical \& Biophysical Research Communications.67(2):610-6.

Nicholls, P. 1976. The effect of formate on cytochrome aa3 and on electron transport in the intact respiratory chain. Biochimica et Biophysica Acta.430(1):13-29.

Nicita, F., Verrotti, A., Pruna, D., Striano, P., Capovilla, G., Savasta, S., Sparta, M.V., Parisi, P., Parlapiano, G., Tarani, L., and Spalice, A. 2014. Seizures in fetal alcohol spectrum disorders: evaluation of clinical, electroencephalographic, and neuroradiologic features in a pediatric case series. Epilepsia 55(6): e60e66.

Noker, P.E., Eells, J.T., and Tephly, T.R. 1980. Methanol toxicity: treatment with folic acid and 5-formyl tetrahydrofolic acid. Alcoholism: Clinical \& Experimental Research 4(4): 378-383.

Noland, J.S., Singer, L.T., Arendt, R.E., Minnes, S., Short, E.J., and Bearer, C.F. 2003. Executive functioning in preschool-age children prenatally exposed to alcohol, cocaine, and marijuana. Alcoholism: Clinical \& Experimental Research 27(4): 647-656.

Palese, M. and Tephly, T.R. 1975. Metabolism of formate in the rat. Journal of Toxicology \& Environmental Health.1(1):13-24.

Pei, J., Denys, K., Hughes, J., and Rasmussen, C. 2011. Mental health issues in fetal alcohol spectrum disorder. Journal of Mental Health 20(5): 438-448.

Peterson, J., Kirchner, H.L., Xue, W., Minnes, S., Singer, L.T., and Bearer, C.F. 2008. Fatty acid ethyl esters in meconium are associated with poorer neurodevelopmental outcomes to two years of age. Journal of Pediatrics 152(6): 788-792.

Pinazo-Duran, M.D., Renau-Piqueras, J., and Guerri, C. 1993. Developmental changes in the optic nerve related to ethanol consumption in pregnant rats: analysis of the ethanol-exposed optic nerve. Teratology 48(4): 305-322.

Pinazo-Duran, M.D., Renau-Piqueras, J., Guerri, C., and Stromland, K. 1997. Optic nerve hypoplasia in fetal alcohol syndrome: an update. European Journal of Ophthalmology 7(3): 262-270.

Ponnappa, B.C., Elingson, J.S., Hoeck, J.B., and Rubin, E. Intracellular accumulation of fatty acid ethyl esters inhibits pancreatic protein synthesis . Gastroenterology 106, A976. 1994.

Ref Type: Abstract

Pragst, F., Auwaerter, V., Sporkert, F., and Spiegel, K. 2001. Analysis of fatty acid ethyl esters in hair as possible markers of chronically elevated alcohol consumption by headspace solid-phase microextraction (HS-SPME) and gas chromatography-mass spectrometry (GC-MS). Forensic Science International 121(12): 76-88.

Prasad, P.D., Ramamoorthy, S., Leibach, F.H., and Ganapathy, V. 1995. Molecular cloning of the human placental folate transporter. Biochemical \& Biophysical Research Communications 206(2): 681-687.

Public Health Agency of Canada. A Sensible Guide to a Healthy Pregnancy. Public Health Agency of 
FASD: Folic acid and Formic Acid An unholy alliance in the alcohol abusing mother.

Canada, Ottawa, Ontario, K1A 0K9, Canada . 2012. 29-3-2017.

http://www.phac-aspc.gc.ca/hp-gs/guide/assets/pdf/hpguide-eng.pdf. Accessed 29march 2017

Ramsay, M. 2010. Genetic and epigenetic insights into fetal alcohol spectrum disorders. Genome Medicine 2(4): 27.

Randall, C.L. and Anton, R.F. 1984. Aspirin reduces alcohol-induced prenatal mortality and malformations in mice. Alcoholism: Clinical \& Experimental Research 8(6): 513-515.

Rasheed, A., Hines, R.N., and Carver-May, D.G. 1997. Variation in induction of human placental CYP2E1: possible role in susceptibility to fetal alcohol syndrome? Toxicology \& Applied Pharmacology 144(2): 396400.

Roberto, M., Treistman, S.N., Pietrzykowski, A.Z., Weiner, J., Galindo, R., Mameli, M., Valenzuela, F., Zhu, P.J., Lovinger, D., Zhang, T.A., Hendricson, A.H., Morrisett, R., and Siggins, G.R. 2006. Actions of acute and chronic ethanol on presynaptic terminals. Alcoholism: Clinical \& Experimental Research.30(2):222-32.

Roe, O. 1955. The metabolism and toxicity of methanol. Pharmacol.Rev. 7: 399-412.

Roine, R.P., Eriksson, C.J., likahri, R., Penttila, A., and Salaspuro, M. 1989. Methanol as a marker of alcohol abuse. Alcoholism 13: 172-175.

Safi, J., Joyeux, L., and Chalouhi, G.E. 2012. Periconceptional folate deficiency and implications in neural tube defects. Journal of Pregnancy 2012: 295083.

Sarmah, S., Muralidharan, P., and Marrs, J.A. 2016. Common congenital anomalies: Environmental causes and prevention with folic acid containing multivitamins. . Birth Defects Research 108(Part C): 274-286.

Seme, M.T., Summerfelt, P., Henry, M.M., Neitz, J., and Eells, J.T. 1999. Formate-induced inhibition of photoreceptor function in methanol intoxication. Journal of Pharmacology \& Experimental Therapeutics 289(1): 361-370.

Seme, M.T., Summerfelt, P., Neitz, J., Eells, J.T., and Henry, M.M. 2001. Differential recovery of retinal function after mitochondrial inhibition by methanol intoxication. Investigative Ophthalmology \& Visual Science 42(3): 834-841.

Sharpe, J.A., Hostovsky, M., Bilbao, J.M., and Rewcastle, N.B. 1982. Methanol optic neuropathy: a histopathological study. Neurology.32(10):1093-100.

Skogerbo, A., Kesmodel, U.S., Wimberley, T., Stovring, H., Bertrand, J., Landro, N.I., and Mortensen, E.L. 2012. The effects of low to moderate alcohol consumption and binge drinking in early pregnancy on executive function in 5-year-old children.. BJOG: An International Journal of Obstetrics \& Gynaecology 119(10): 1201-1210.

Smith, M., Hopkinson, D.A., and Harris, H. 1971. Developmental changes and polymorphism in human alcohol dehydrogenase. Annals of Human Genetics 34(3): 251-271.

Sogut, I., Uysal, O., Oglakci, A., Yucel, F., Kartkaya, K., and Kanbak, G. 2017. Prenatal alcohol-induced neuroapoptosis in rat brain cerebral cortex: protective effect of folic acid and betaine. Childs Nervous 
FASD: Folic acid and Formic Acid An unholy alliance in the alcohol abusing mother.

System 33(3): 407-417.

Sokol, R.J., Dalaney-Black, V., and Nordstrom, B. 2003. Fetal alcohol spectrum disorder. JAMA 290(22): 2996-2999.

Sokoro, A.A., Zhang, Z., Eichhorst, J.C., Zello, G.A., House, J.D., Alcorn, J., and Lehotay, D.C. 2008. Formate pharmacokinetics during formate administration in folate-deficient young swine. Metabolism: Clinical \& Experimental 57(7): 920-926.

Solanky, N., Requena, J.A., D'Souza, S.W., Sibley, C.P., and Glazier, J.D. 2010. Expression of folate transporters in human placenta and implications for homocysteine metabolism. Placenta 31(2): 134-143.

Sowell, E.R., Charness, M.E., and Riley, E.P. 2014. Pregnancy: No safe level of alcohol. Nature 513(7517): 172.

Sprung, R., Bonte, W., and Lesch, O.M. 1988a. Ein bisher verkannter Bestandteil aller alkoholischen Getranke. Ein neue biochemiche Annaherung an das Problem des chronischen Alkoholismus (Methanol-an up-to-now neglected constituent of all alcoholic beverages. A new biochemical approach to the problem of chronic alcoholism) [German]. Wiener Klinische Wochenschrift 100(9): 282-288.

Sprung, R., Bonte, W., and Lesch, O.M. 1988b. Ein bisher verkannter Bestandteil aller alkoholischen Getranke. Ein neue biochemiche Annaherung an das Problem des chronischen Alkoholismus [Methanol-an up-to-now neglected constituent of all alcoholic beverages. A new biochemical approach to the problem of chronic alcoholism]. [German]. Wiener Klinische Wochenschrift 100(9): 282-288.

Stanley, E.L., Hume, R., and Coughtrie, M.W. 2005. Expression profiling of human fetal cytosolic sulfotransferases involved in steroid and thyroid hormone metabolism and in detoxification. Molecular \& Cellular Endocrinology 240(1-2): 32-42.

Stark, K.D., Pawlosky, R.J., Sokol, R.J., Hannigan, J.H., and Salem, N., Jr. 2007. Maternal smoking is associated with decreased 5-methyltetrahydrofolate in cord plasma. American Journal of Clinical Nutrition 85(3): 796-802.

Stolzenberg-Solomon, R.Z., Albanes, D., Nieto, F.J., Hartman, T.J., Tangrea, J.A., Rautalahti, M., Sehlub, J., Virtamo, J., and Taylor, P.R. 1999. Pancreatic cancer risk and nutrition-related methyl-group availability indicators in male smokers. Journal of the National Cancer Institute 91(6): 535-541.

Stromland, K. 1985. Ocular abnormalities in the fetal alcohol syndrome. Acta Ophthalmologica Supplementum 171: 1-50.

Stromland, K. 1987. Ocular involvement in the fetal alcohol syndrome. Survey of Ophthalmology 31(4): 277-284.

Stromland, K. and Pinazo-Duran, M.D. 1994. Optic nerve hypoplasia: comparative effects in children and rats exposed to alcohol during pregnancy. Teratology 50(2): 100-111.

Stromland, K. and Pinazo-Duran, M.D. 2002. Ophthalmic involvement in the fetal alcohol syndrome: clinical and animal model studies. Alcohol Alcohol 37(1): 2-8. 
FASD: Folic acid and Formic Acid An unholy alliance in the alcohol abusing mother.

Stromland, K. and Sundelin, K. 1996. Paediatric and ophthalmologic observations in offspring of alcohol abusing mothers. Acta Paediatrica 85(12): 1463-1468.

Sun, A.Y. and Sun, G.Y. 2001. Ethanol and oxidative mechanisms in the brain. Journal of Biomedical Science.8(1):37-43.

Szczepiorkowski, Z.M., Dickersin, G.R., and Laposata, M. 1995. Fatty acid ethyl esters decrease human hepatoblastoma cell proliferation and protein synthesis. Gastroenterology 108(2): 515-522.

Tephly, T.R. and and McMartin, K.E. 1974. Methanol metabolism and toxicity. In Aspartame. Physiology and Biochemistry. Edited by L.D. Stegink and and Filer Jr L.J. Markel Deccer, New York/Basel pp. 111-140.

Tephly, T.R. 1991. The toxicity of methanol. Life Sciences 48(11): 1031-1041.

Thakur, S. and Kaur, J. 2015a. Regulation at multiple levels control the expression of folate transporters in liver cells in conditions of ethanol exposure and folate deficiency. Biofactors 41(4): 232-241.

Thakur, S. and Kaur, J. 2015b. Regulation at multiple levels control the expression of folate transporters in liver cells in conditions of ethanol exposure and folate deficiency. Biofactors 41(4): 232-241.

Treichel, J.L., Henry, M.M., Skumatz, C.M., Eells, J.T., and Burke, J.M. 2004. Antioxidants and ocular cell type differences in cytoprotection from formic acid toxicity in vitro. Toxicological Sciences.82(1):183-92.

Underbjerg, M., Kesmodel, U.S., Landro, N.I., Bakketeig, L., Grove, J., Wimberley, T., Kilburn, T.R., Svaerke, C., Thorsen, P., and Mortensen, E.L. 2012. The effects of low to moderate alcohol consumption and binge drinking in early pregnancy on selective and sustained attention in 5-year-old children. . BJOG: An International Journal of Obstetrics \& Gynaecology 119(10): 1211-1221.

Upadhya, S.C., Tirumalai, P.S., Boyd, M.R., Mori, T., and Ravindranath, V. 2000. Cytochrome P4502E (CYP2E) in brain: constitutive expression, induction by ethanol and localization by fluorescence in situ hybridization. Archives of Biochemistry \& Biophysics.373(1):23-34.

Vangipuram, S.D., Grever, W.E., Parker, G.C., and Lyman, W.D. 2008. Ethanol increases fetal human neurosphere size and alters adhesion molecule gene expression. Alcoholism: Clinical \& Experimental Research 32(2): 339-347.

Vasiliou, V., Ziegler, T.L., Bludeau, P., Petersen, D.R., Gonzalez, F.J., and Deitrich, R.A. 2006. CYP2E1 and catalase influence ethanol sensitivity in the central nervous system. Pharmacogenetics \& Genomics.16(1):51-8.

Walling, C. 1975. Fenton's reagent revisited. Accounts of Chemical Research 8(4): 125-131.

Werner, J., Laposata, M., Fernandez-del, C.C., Saghir, M., lozzo, R.V., Lewandrowski, K.B., and Warshaw, A.L. 1997. Pancreatic injury in rats induced by fatty acid ethyl ester, a nonoxidative metabolite of alcohol. Gastroenterology 113(1): 286-294.

Wood C.A. and Buller F 1904. Poisoning by wood alcohol: Cases of death and bindness from Columbian sprits and other methylated preparations. JAMA 43: 972-977. 
FASD: Folic acid and Formic Acid An unholy alliance in the alcohol abusing mother.

861 Yadav, S., Dhawan, A., Singh, R.L., Seth, P.K., and Parmar, D. 2006. Expression of constitutive and 862 inducible cytochrome P450 2E1 in rat brain. Molecular \& Cellular Biochemistry.286(1-2):171-80.

863 Yasuda, S., Hasui, S., Kobayashi, M., Itagaki, S., Hirano, T., and Iseki, K. 2008a. The mechanism of carrier864 mediated transport of folates in BeWo cells: the involvement of heme carrier protein 1 in placental folate 865 transport. Bioscience, Biotechnology \& Biochemistry 72(2): 329-334.

866 Yasuda, S., Hasui, S., Yamamoto, C., Yoshioka, C., Kobayashi, M., Itagaki, S., Hirano, T., and Iseki, K. $2008 \mathrm{~b}$. 867 Placental folate transport during pregnancy. Bioscience, Biotechnology \& Biochemistry 72(9): 2277-2284.

868 Yelin, R., Kot, H., Yelin, D., and Fainsod, A. 2007. Early molecular effects of ethanol during vertebrate 869 embryogenesis. Differentiation 75(5): 393-403.

870 Ylikorkala, O., Halmesmaki, E., and Viinikka, L. 1988. Urinary prostacyclin and thromboxane metabolites 871 in drinking pregnant women and in their infants: relations to the fetal alcohol effects. Obstetrics \& 872 Gynecology 71(1): 61-66.

873 Zelner, I. and Koren, G. 2013. Pharmacokinetics of ethanol in the maternal-fetal unit. Journal of 874 Population Therapeutics \& Clinical Pharmacology 20(3): e259-e265.

875 Zimatkin, S.M., Pronko, S.P., Vasiliou, V., Gonzalez, F.J., and Deitrich, R.A. 2006. Enzymatic mechanisms of 876 ethanol oxidation in the brain. Alcoholism: Clinical \& Experimental Research.30(9):1500-5. 
FASD: Folic acid and Formic Acid An unholy alliance in the alcohol abusing mother.

$880 \quad$ Titles

881

882

883

884

885

886

887

888

889

890

891

892

Figure 1: Methanol metabolism

Figure 2: Metabolism of formate by folate-dependent pathway

Figure 3: FASD - Gestation continuum

Figure 4: Implications of different studi 
$\stackrel{\mathrm{CH}_{3}-\mathrm{OH}}{\mathrm{H}_{2} \mathrm{C}=\mathrm{O}} \underset{\mathrm{ADH}}{\longrightarrow}$ formaldehyde $\stackrel{\mathrm{ALDH}}{\longrightarrow}$ formic acid $\underset{\text { folic acid }}{\mathrm{HO}-\mathrm{HC}=\mathrm{O}} \stackrel{\substack{\text { formyl THF } \\ \text { synthetase }}}{\mathrm{CO}_{2}}+\mathrm{H}_{2} \mathrm{O}$

Figure 1 Methanol metabolism

$152 \times 16 \mathrm{~mm}(300 \times 300 \mathrm{DPI})$ 


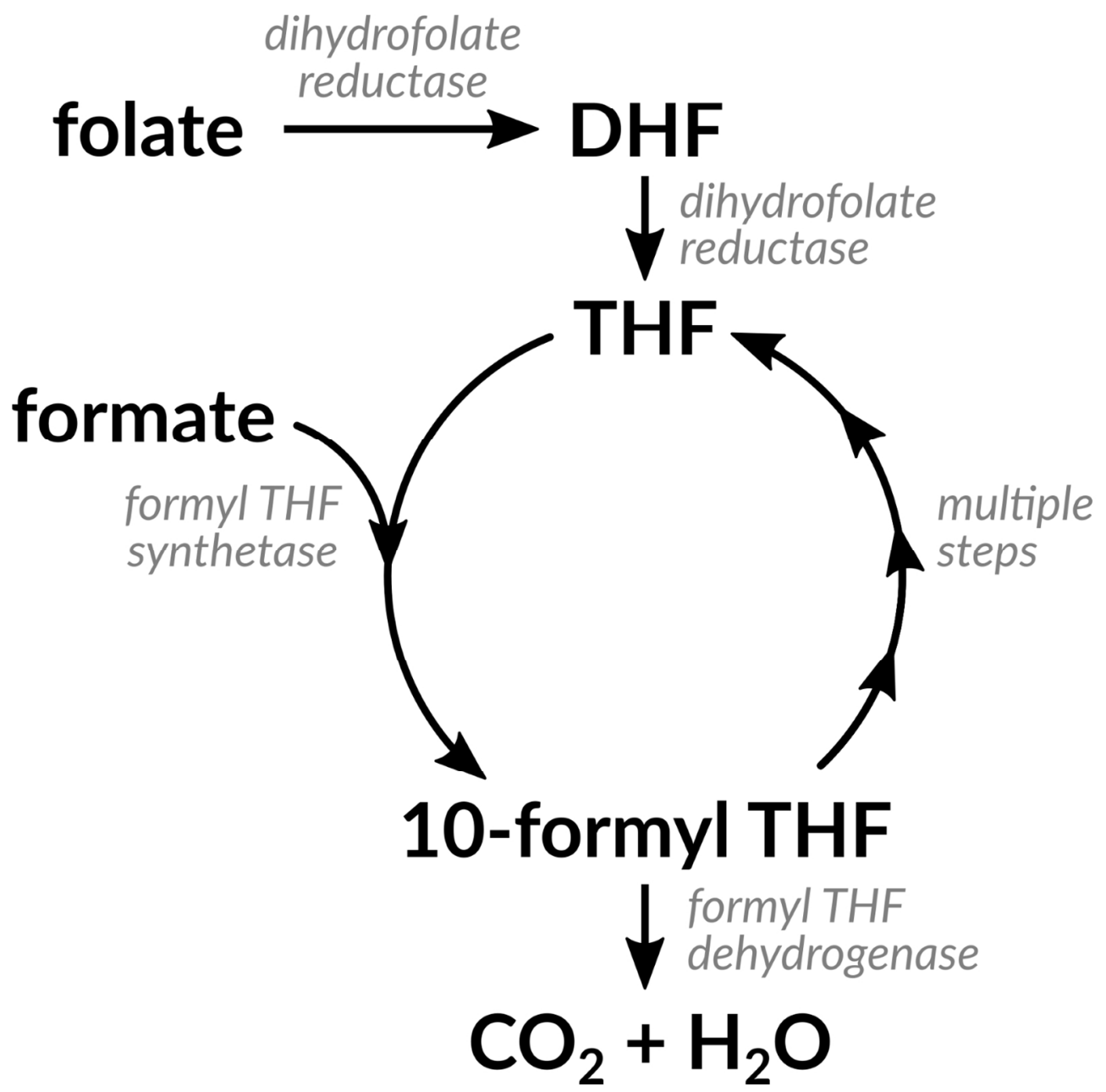

Figure 2: Metabolism of formate by folate-dependent pathway $139 \times 139 \mathrm{~mm}(300 \times 300$ DPI $)$ 


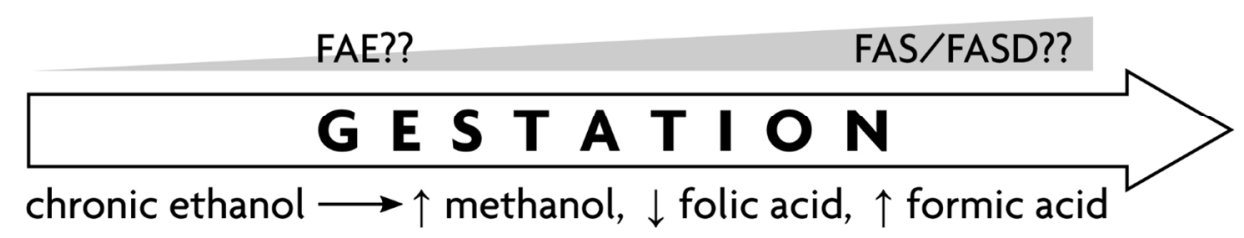

Figure 3: FASD - Gestation continuum $403 \times 79 \mathrm{~mm}$ (96 x 96 DPI) 
Formic acid is produced locally in the fetal brain, and/or it crosses the placenta from mother to fetus

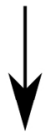

Increased formic acid concentration will lead to formation of lesions at the local site

Lesions can have significant functional impact in these brain tissues/organs

Figure 4: Implications of different studies $156 \times 84 \mathrm{~mm}(300 \times 300 \mathrm{DPI})$ 